\title{
High Efficiency Inverted Metamorphic (IMM) Solar Cells
}

\author{
J. Boisvert, D. Law, R. King, E. Rehder, P. Chiu, D. Bhusari, C. Fetzer, X. Liu, W. Hong S. Mesropian, R. \\ Woo, K. Edmondson, H. Cotal, D. Krut, S. Singer, S. Wierman, and N. H. Karam \\ Spectrolab, Inc. 12500 Gladstone Ave., Sylmar, CA 91342 U.S.A.
}

\begin{abstract}
High efficiency Inverted Metamorphic (IMM) multi-junction solar cells have been under development at Spectrolab for use in space and near space applications This paper reviews the present state-of-the-art of this technology at Spectrolab with an emphasis on performance characterization data at in-flight operating conditions. Large area IMM3J and IMM4J solar cells with $1 \mathrm{X}$ AM0 efficiency greater than $32 \%$ at $28{ }^{\circ} \mathrm{C}$ have been fabricated and characterized. Degradation factors after exposure to $1 \mathrm{MeV}$ electron irradiation for both IMM3J and IMM4J technologies is presented. A coupon utilizing large area, IMM solar cells has been assembled and subjected to thermal cycling. Pre-and post thermal cycling data have been collected. Preliminary temperature cycling data indicate that a small coupon populated with strings of these cells suffered no degradation.
\end{abstract}

Index Terms — space, photovoltaic, multi-junction, IMM

\section{INTRODUCTION}

Spectrolab has developed high efficiency Inverted Metamorphic (IMM) multi-junction solar cells [1-2] for use in space and near space applications [3-4]. In this paper, we review the status of the technology at Spectrolab with emphasis placed on performance at in flight operating conditions.

Under U.S. government funding, a coupon utilizing large area, IMM solar cells has been assembled and subjected to thermal cycling. Pre-and post thermal cycling data have been collected and is presented as well. Cross sections of IMM solar cells are shown in Fig. 1.

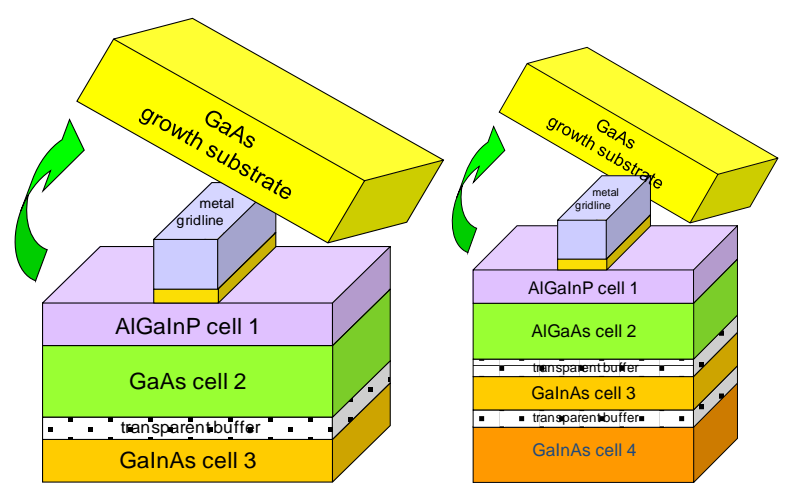

Fig. 1. Typical IMM3J and IMM4J solar cell grown in an inverted configuration on a Ge or GaAs substrate. The grown structure is affixed to a handle (not shown) and the growth substrate removed.

IMM space cells are composed of three or four constituent III-V-based subcells and are grown in an inverted configuration. Large production MOVPE reactors are used to grow these solar cells on $100 \mathrm{~mm}$ substrates. The widest bandgap alloy (top cell) is grown first followed by a middle cell, buffer layers and finally either one or two low bandgap metamorphic cells that are lattice mismatched to the growth substrate. Subsequent wafer processing places the inverted multijunction solar cell in an upright configuration and the growth substrate is removed. Processes typical of standard, high-volume semiconductor wafer processing are used to complete fabrication. Cell-Interconnect-Coverglass (CICs) are then assembled based on typical space-qualified production assembly processes.

\section{TEST ARTICLES}

Large area $\left(24 \mathrm{~cm}^{2}\right)$ cells for use in $1 \mathrm{X}$ AM0 environments have been fabricated and tested. These cells were subsequently assembled into CIC assemblies and affixed to rigid aluminum honeycomb substrates for characterization before and after thermal cycling.

Small area $2 \times 2 \mathrm{~cm}^{2}$ cells were fabricated for radiation exposure at the Boeing Radiation Effects Laboratory. The cells were characterized both before and after exposure to 1 $\mathrm{MeV}$ electron fluences of $1 \times 10^{14} / \mathrm{cm}^{2} ; 5 \times 10^{14} / \mathrm{cm}^{2}$; and $1 \times 10^{15} / \mathrm{cm}^{2}$.

\section{CHARACTERIZATION DATA}

Typical current-bias characteristics for Spectrolab IMM3J solar cell and CICs under 1X AM0 solar simulator illumination (LIV data) are shown in Fig. 2. These simulator data were collected on a Spectrolab AX-25 solar simulator using calibrated IMM3J Lear Jet flight standards; to date no IMM balloon flight standards have been flown. A CMG coverglass with an enhanced AR coating to provide protection from atomic oxygen degradation on-orbit was used to assemble the CIC. 


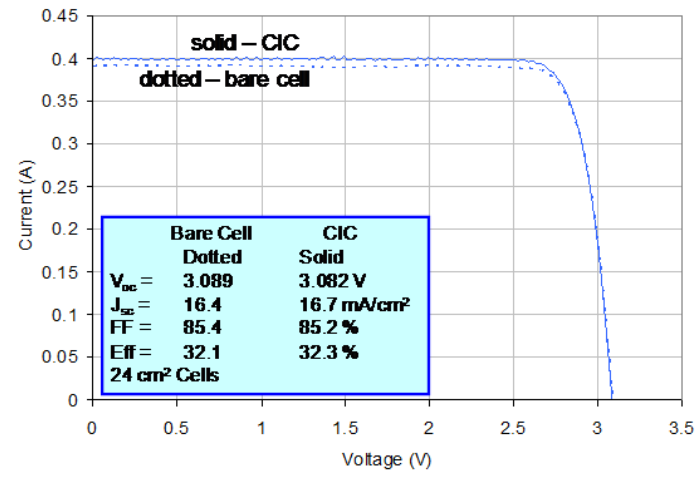

Fig. 2. The LIV characteristics of a $24 \mathrm{~cm}^{2}$ IMM3J cell and CIC at $28{ }^{\circ} \mathrm{C}$. The reported efficiency is based on IMM Lear Jet calibration standards.

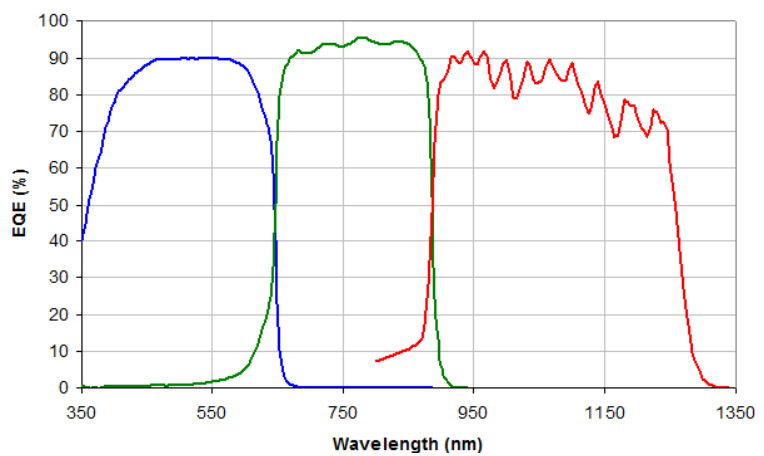

Fig. 3. Typical external quantum efficiency characteristics collected on the IMM3J solar cells shown in Fig. 2.

Typical spectral response measurements for these IMM3J cells are shown in Fig. 3, and are consistent with the measured $\mathrm{J}_{\mathrm{sc}}$ data shown in Fig. 2 when convolved with an AM0 spectrum.

Typical IMM4J cell and CIC LIV data are shown in Fig. 4 and EQE data for the cell is shown in Fig. 5. These data also exhibit consistent $\mathrm{J}_{\mathrm{sc}}$ values between $\mathrm{AX}-25$ and EQE measurements.

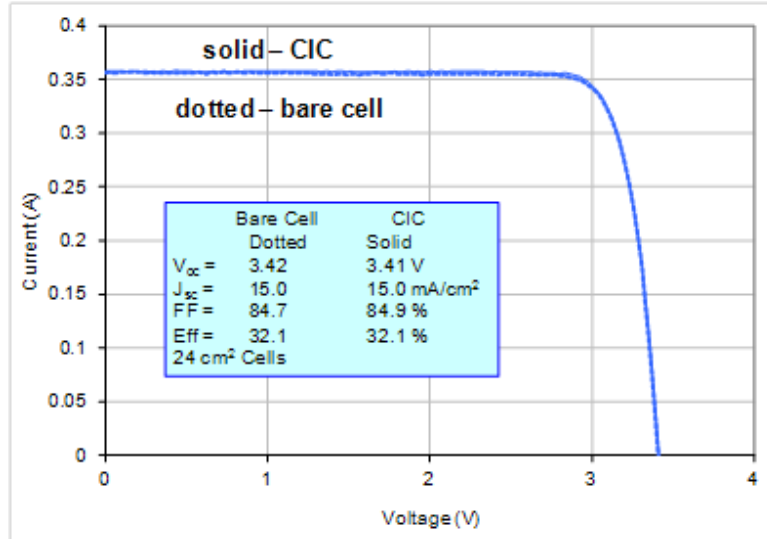

Fig. 4. The LIV characteristic of a 24- $\mathrm{cm}^{2}$ IMM4J cell and CIC at $28^{\circ} \mathrm{C}$. The reported efficiency is based on IMM Lear Jet calibration standards.

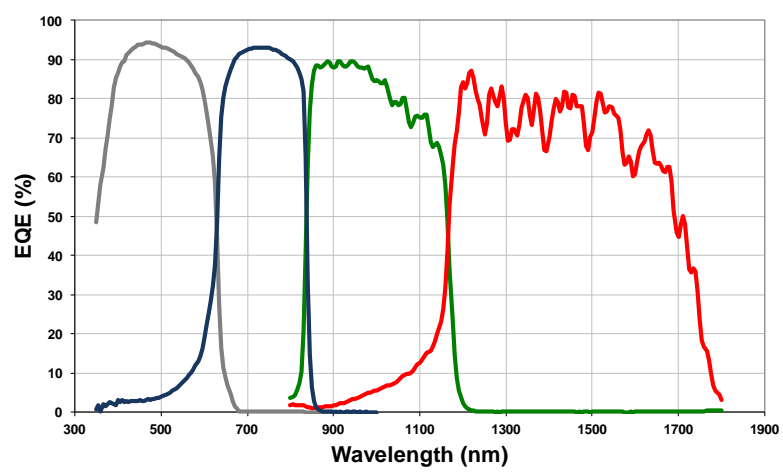

Fig. 5. Typical external quantum efficiency characteristics collected on the IMM4J solar cells shown in Fig. 4.

A coupon of large area IMM CICs was assembled and characterized for performance before and after temperature cycling. The coupon is shown in Fig. 6 and it consists of a string of six UTJ control CICs, a string of seven IMM3J CICs and a string of four IMM4J CICs.

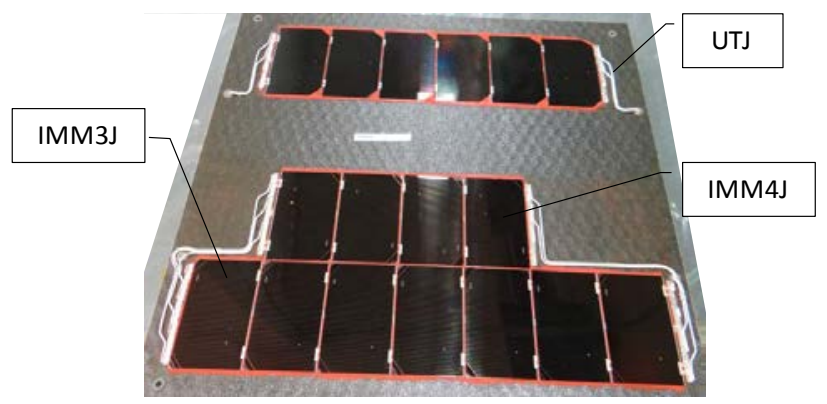

Fig. 6. An assembled IMM coupon consisting of large area IMM3J, IMM4J solar cell CICs and UTJ controls.

Forward bias electroluminescence images were collected on each CIC prior to temperature cycling. A photograph of an IMM3J cell under forward bias current injection is shown in Fig. 7.

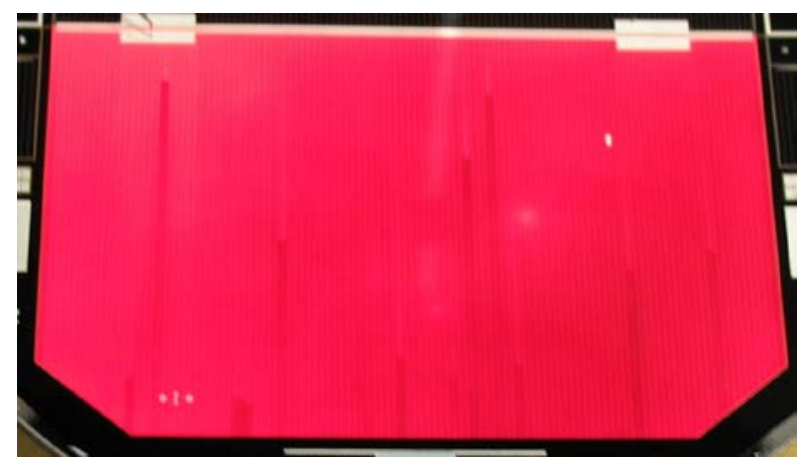

Fig. 7. A 24- $\mathrm{cm}^{2}$ IMM3J cell under forward bias current injection 
This coupon is being temperature cycled from approximately $\pm 100{ }^{\circ} \mathrm{C}$ and characterized at regular intervals. To date, the IMM3J and IMM4J strings display no change in performance after break points at 98, 836, and 1,700 thermal cycles as measured on a Spectrolab Large Area Pulsed Solar Simulator (LAPSS). The LAPSS was calibrated with respect to UTJ standards. The pre/post characterization data for the IMM3J and IMM4J strings are shown in Fig. 8 and Fig. 9 respectively. This coupon will continue to accumulate thermal cycles until it reaches 11,000 cycles - the requirement for AIAA-S111-2005 qualification.

Small area $2 \times 2 \mathrm{~cm}^{2}$ cells were fabricated for radiation exposure at the Boeing Radiation Effects Laboratory. The cells were characterized both before and after exposure to 1 $\mathrm{MeV}$ electron fluences of $1 \times 10^{14} / \mathrm{cm}^{2} ; 5 \times 10^{14} / \mathrm{cm}^{2}$; and $1 \times 10^{15} / \mathrm{cm}^{2}$. The normalized (to beginning of life) power retention versus fluence characteristics for both IMM3J and IMM4J cells are shown in Fig.10. NPmp for the IMM3J and IMM4J cell are 0.84 and 0.80 at $1 \times 10^{15} / \mathrm{cm}^{2}$ fluence respectively. The radiation tolerance exhibited by IMM3J is nearly equivalent to that exhibited by upright triple junction solar cells now in production. We anticipate that adjustments in cell design in the IMM4J will soon elevate the NPmp to parity with respect to the upright $3 \mathrm{~J}$ and IMM3J technologies.

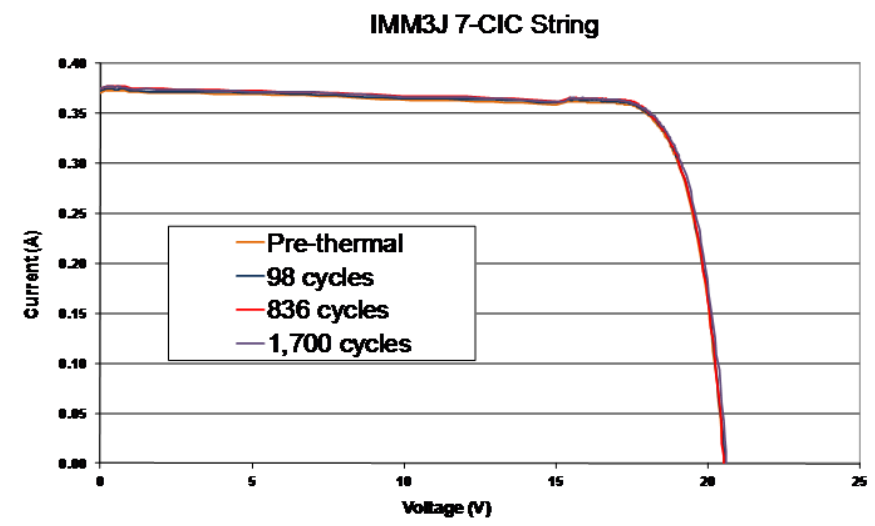

Fig. 8. LAPSS LIV data collected on an IMM3J string after several break points. The data shows no degradation in performance of the coupon string.

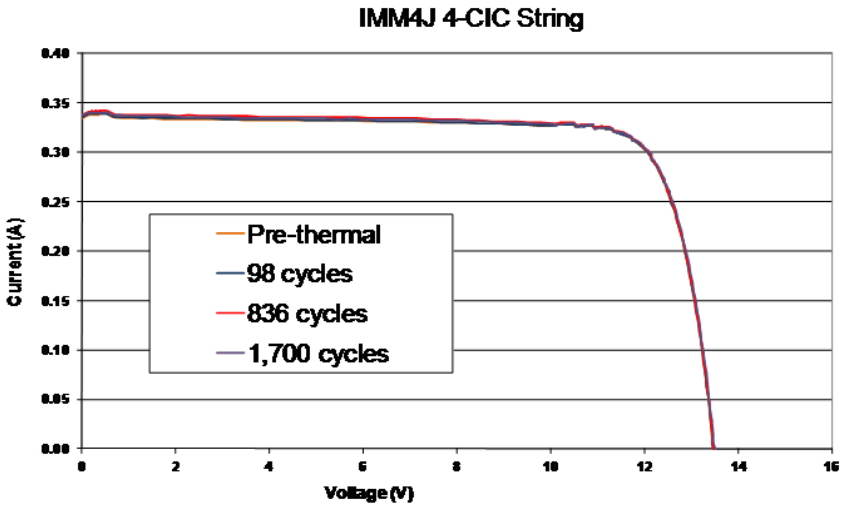

Fig. 9. LAPSS LIV data collected on an IMM4J string after several break points. The data shows no degradation in performance of the coupon string.

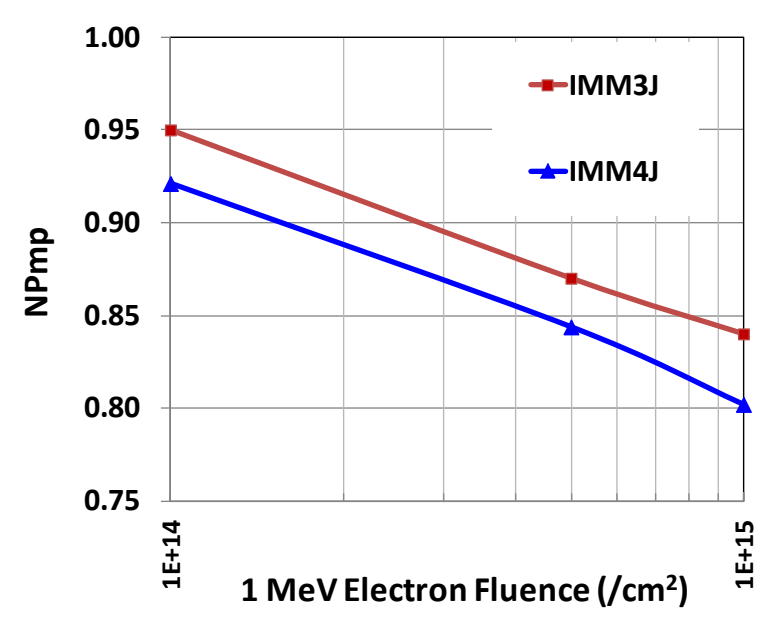

Fig. 10. The normalized power versus electron fluence characteristics of small area IMM3J and IMM4J space solar cells.

\section{CONCLUSION}

Spectrolab continues development of high efficiency IMM solar cell technology for space and near space applications. IMM solar cells with $1 \mathrm{X}$ AM0 efficiency greater than $32 \%$ at $28^{\circ} \mathrm{C}$ have been demonstrated. Preliminary temperature cycling data indicate that a small coupon populated with strings of these cells suffered no degradation. Radiation degradation factors indicate that IMM cell technology is approaching tolerance levels demonstrated by upright triple junction solar cells now in production at Spectrolab.

\section{ACKNOWLEDGEMENT}

The authors would like to thank the entire R\&D team at Spectrolab. Support from the Air Force Research Laboratory Space Vehicles Directorate, the US Government and from Boeing Internal Research and Development funds is gratefully acknowledged.

\section{REFERENCES}

[1] M. W. Wanlass, S. P. Ahrenkiel, R. K. Ahrenkiel, D. S. Albin, J. J. Carapella, A. Duda, J. F. Geisz, S. Kurtz, T. Moriarty, R. J. Wehrer, and B.Wernsman, in 31st IEEE Photovoltaic Specialists Conference, 2005, p. 530.

[2] R. R. King, D. C. Law, C. M. Fetzer, R. A. Sherif, K. M. Edmondson, S. Kurtz, G. S. Kinsey, H. L. Cotal, D. D. Krut, J. H. Ermer, and N. H. Karam, in 20th European Photovoltaic Solar Energy Conference, 2005. p. 118.

[3] H. Yoon, M. Haddad, S. Mesropian, J. Yen, K. Edmondson, D. Law, R. King, D. Bhusari, A. Boca, N. Karam, in $33^{\text {rd }}$ IEEE Photovoltaic Specialists Conference, 2006, p. 1.

[4] J. Boisvert, D. Law, R. King, D. Bhusari, X. Liu, A. Zakaria, W. Hong, S. Mesropian, D. Larrabee, R. Woo, A. Boca, K. Edmondson, D. Krut, D. Peterson, K. Rouhani, B. Benedikt, and N.H. Karam, in 35th IEEE Photovoltaic Specialists Conference, 2010, p. 12 